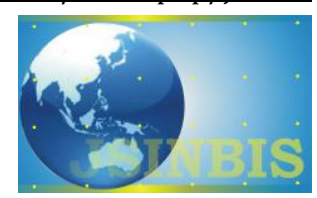

\title{
Rancang Bangun Tata Kelola Kinerja Perguruan Tinggi Menggunakan IT Balanced Scorecard
}

\author{
Achmad Solechan ${ }^{\mathrm{a}^{*}}$, Teguh Prasandy \\ ${ }^{a, b}$ Jurusan Sistem Informasi, STMIK Provisi Semarang
}

Naskah Diterima : 1 Maret 2016; Diterima Publikasi : 5 Mei 2016

DOI: $10.21456 /$ vol6iss1pp84-89

\begin{abstract}
This research focuses on the design of governance of college performance using IT Balanced Scorecard using online questionnaires to stakeholders in the college of Perspective Contributions Organization, User Orientation, Operational Excellence and Orientation in the Future. System development method used in this study using the method of using the waterfall SDLC. By using the information system of governance of college performance using IT Balance Scorecard, data processing faster and more efficient and quicker in making an evaluation report IT governance, helping the presentation of information and error reduction calculations, the transaction data maintained intact its security, is able to complete the process preparing reports quickly, speeding up the process of calculation and the conclusions of the assessment of the performance of the college.
\end{abstract}

Keywords: information Technology Governance; IT Balanced Scorecard; Colleges

\begin{abstract}
Abstrak
Penelitian ini fokus pada rancang bangun tata kelola kinerja perguruan tinggi menggunakan IT Balanced Scorecard dengan menggunakan penyebaran kuesioner online kepada pemangku kepentingan di perguruan tinggi tentang Perspektif Kontribusi Organisasi, Orientasi Pengguna, Keunggulan Operasional dan Orientasi di Masa Depan. Metode pengembangan sistem yang akan digunakan dalam penelitian ini menggunakan metode SDLC menggunakan waterfall. Dengan menggunakan sistem informasi tata kelola kinerja perguruan tinggi menggunakan IT Balance Scorecard, pengolahan data lebih cepat dan efisien sehingga lebih cepat dalam pembuatan laporan evaluasi tata kelola IT, membantu penyajian informasi dan pengurangan kesalahan perhitungan, data-data transaksi terjaga utuh keamanannya, mampu menyelesaikan proses pembuatan laporan dengan cepat, mempercepat proses perhitungan serta kesimpulan dari penilaian kinerja perguruan tinggi.
\end{abstract}

Kata kunci : tata kelola teknologi informasi, IT Balanced Scorecard, dan perguruan tinggi

\section{Pendahuluan}

Sekarang ini hampir semua perguruan tinggi menerapkan penggunaan teknologi informasi sebagai pendukung kegiatan operasional pengajaran serta administrasi pelaksanaan unit terkait dengan kegiatan usaha institusi. Menurut Alberch dan Pirani (2004) bahwa tata kelola teknologi informasi yang dibutuhkan untuk institusi pendidikan tinggi yaitu agar tercipta proses penyebaran ilmu dalam kegiatan pembelajaran yang lebih interaktif dan dinamis, transparasi tata kelola operasional kegiatan institusi, serta peningkatan kinerja berbasis evaluasi dengan penilaian yang transparan, serta keamanan data serta informasi yang berhubungan dengan hak intelektual seseorang. Tata kelola teknologi informasi nantinya akan menjadi jawaban agar apa yang sudah diinvestasikan untuk teknologi informasi agar dapat memberikan hasil yang maksimal dan berguna bagi institusi (Alberch dan Pirani, 2004).

Mengingat semakin ketatnya persaingan di institusi pendidikan khususnya perguruan tinggi swasta yang bergerak di program studi informatika, menyebabkan perguruan tinggi harus menempatkan orientasi pada kepuasan pelanggan (mahasiswa) sebagai tujuan utama. Selain ketatnya persaingan, di

*) Penulis korespondensi: achmad.solechan.semarang@gmail.com 
masa kini dan mendatang akan terus terjadi perubahan pada hal-hal yang terkait dengan masalah ekonomi dan kecenderungannya. Kajian penelitian mengambil obyek pada perguruan tinggi dalam rangka meningkatkan kinerja teknologi informasinya. Hasil pengukuran kinerja dapat digunakan sebagai bahan pertimbangan pengembangan teknologi informasi selanjutnya. Salah satu alat untuk mengukur kinerja teknologi informasi adalah IT balance scorecard yang dapat digunakan untuk mengukur kinerja bisnis dan kinerja IT di perguruan tinggi (Harsono, 2010).

Penelitian ini mengambil obyek penelitian pada Perguruan Tinggi disebabkan karena penganggaran perguruan tinggi sebagian besar tidak didasarkan pada tata kelola yang baik dan konseptual, namun berdasarkan kebutuhan jangka pendek di masingmasing perguruan tinggi. Permasalahan lainnya yaitu berkaitan dengan pemakaian teknologi informasi baik hardware, software maupun brainware (user) dalam pengelolaan teknologi informasi masih belum terkonsep dengan baik dalam pengembangannya.

Untuk menganalisis kinerja perusahaan berkaitan dengan tata kelola IT dapat dilakukan dengan Information Technology Balanced Scorecard (IT Balance Scorecard) yang merupakan suatu sistem manajemen, pengukuran dan pengendalian yang secara cepat, tepat dan komprehensif dapat memberikan pemahaman kepada Pimpinan tentang potret dan pengembangan teknologi informasi di insitusinya. Pengukuran tata kelola IT tersebut dipandang dari empat perspektif yaitu : (1) Perspektif Kontribusi Organisasi berupa : mengkaji data dokumentasi berupa data finansial dan data proyek IT di Perguruan Tinggi; (2) Perspektif Orientasi Pengguna : melakukan penyebaran kuesioner online berkaitan dengan pangsa pasar, reputasi kampus, kualitas pelayanan (jasa) Perguruan Tinggi, dan kepuasan mahasiswa; (3) Perspektif Keunggulan Operasional : melakukan pengisian kuesioner online dan pengkajian operasional bisnis internal dalam pengembangan Teknologi Informasi di Perguruan Tingi, dan (4) Perspektif Orientasi di Masa Depan (Future Orientation) : melakukan penyebaran kuesioner online berkaitan dengan pengukuran kepuasan tenaga pendidik dan kependidikan, serta produktivitas kerja tenaga pendidik dan kependidikan. Selain itu juga dilakukan pengukuran tentang kompensasi tenaga pendidik dan kependidikan, infrastruktur teknologi dan kapabilitas sistem informasi.

\section{Kerangka Teori}

Balanced scorecard terdiri dari 2 kata yaitu balanced (berimbang) dan scorecard yaitu kartu skor. Kartu skor adalah kartu yang digunakan untuk mencatat skor hasil kinerja seseorang. Kartu skor juga dapat digunakan untuk merencanakan skor yang hendak diwujudkan oleh personil di masa depan.
Melalui kartu skor, skor yang hendak diwujudkan oleh personil di masa depan dibandingkan dengan hasil kinerja sesungguhnya. Hasil perbandingan ini digunakan untuk melakukan evaluasi atas kinerja personil yang bersangkutan. Dengan demikian balanced scorecard merupakan alat kontemporer manajemen yang digunakan untuk mendongkrak kemampuan organisasi dalam melipatgandakan kinerja.

Balanced scorecard merupakan sistem manajemen strategis yang menterjemahkan visi dan strategi suatu organisasi kedalam tujuan dan ukuran operasional. Balanced scorecard adalah konsep perencanaan dan implementasi manajemen strategik yang komprehensif yang ditemukan oleh Kaplan dan Norton (2001) terdiri dari empat perspektif yaitu : pelanggan, keuangan, internal dan pembelajaran dan pertumbuhan.

Faktor-faktor penghambat Balanced Scorecard yaitu : (Gasperz, 2002)

1. Tidak banyak orang dalam organisasi yang memahami strategi organisasi mereka.

2. Banyak orang dalam organisasi memiliki tujuan yang tidak terkait dengan strategi organisasi.

3. Waktu, energi, dan uang tidak dialokasikan pada hal-hal yang penting (kritis) dalam organisasi.

4. Manajemen menghabiskan terlalu sedikit waktu untuk strategi organisasi dan terlalu banyak waktu untuk pembuatan keputusan taktis jangka pendek.

Pada tahun 1997, Van Grembergen dan Van Bruggen (2001) mengadopsi balanced scorecard untuk dipergunakan pada Departemen Teknologi Informasi, sehingga terjadi perubahan perspektif pada model tradisional dan model IT Balanced Scorecard yang dapat dilihat pada gambar berikut : (Jogiyanto dan Wily, 2001)

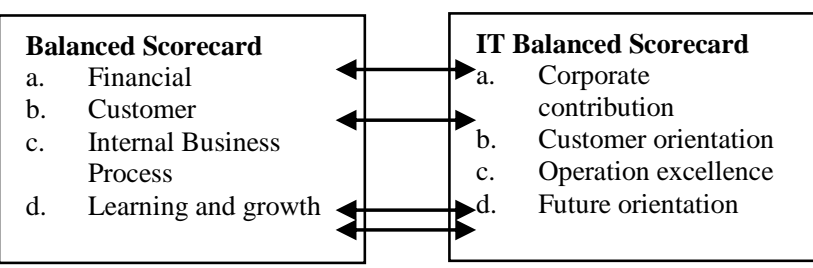

Gambar 1. Perubahan Perspektif Balanced Scorecard Tradisional menjadi IT Balanced Scorecard

Balanced scorecard memiliki keunggulan yang menjadikan sistem manajemen strategik sekarang berbeda dengan sistem manajemen strategik dalam manajamen tradisional. Keunggulan balanced scorecard dalam sistem perencanaan strategik mampu menghasilkan rencana strategik yang memiliki karakteristik antara lain : (Norton dan Kaplan, 2000)

a. Komprehensif

Balanced scorecard memperluas perspektif yang dicakup dalam perencanaan strategik dari yang sebelumnya hanya terbatas pada perspektif keuangan, meluas ke tiga perspektif yang lain 
yaitu customer, proses bisnis internal serta pembelajaran dan pertumbuhan.

b. Koheren

Balanced scorecard mewajibkan personal untuk membangun hubungan sebab akibat diantara berbagai sasaran strategik yang dihasilkan dalam perencanaan strategik. Setiap sasaran strategik yang ditetapkan dalam persepsktif non keuangan harus mempunyai hubungan kausal dengan sasaran keuangan, baik secara langsung maupun tidak langsung.

c. Seimbang

Keseimbangan sasaran strategik yang dihasilkan oleh sistem perencanaan strategik penting untuk menghasilkan kinerja keuangan berjangka panjang.

d. Terukur

Balanced scorecard mengukur sasaran-sasaran strategik yang sulit untuk diukur. Dalam pendekatan balanced scorecard sasaran ketiga perspektif non keuangan ditentukan ukurannya agar dapat dikelola, sehingga dapat diwujudkan.

\section{Metodologi}

\subsection{Metode Pengumpulan Data}

Penelitian ini menggunakan beberapa teknik pengumpulan data yang digunakan dalam penelitian ini adalah (1) Dokumentasi adalah metode pengumpulan data yang dilakukan melalui catatancatatan yang ada dan sudah tersedia seperti data aplikasi konsumen dan lain-lain. Dokumentasi yang digunakan adalah dokumentasi keuangan yang mengkaji data finansial dan data proyek IT di perguruan tinggi yang diobservasi, (2) Kuesioner (angket) adalah cara pengumpulan data dengan menggunakan daftar isian atau daftar pertanyaan secara online yang telah disiapkan dan disusun sedemikian rupa sehingga calon responden hanya tinggal mengisi atau menandainya dengan mudah dan cepat. Kuesioner dilakukan sebagai feedback kepada mahasiswa untuk mengetahui pangsa pasar, reputasi kampus, kualitas pelayanan (jasa) pada perguruan tinggi yang diobservasi dan kepuasan mahasiswa, Di samping itu dilakukan penyebaran kuesioner kepada tenaga pendidik dan kependidikan untuk pengukuran kepuasan tenaga pendidik dan kependidikan, serta produktivitas kerja tenaga pendidik dan kependidikan. Selain itu juga dilakukan pengukuran tentang kompensasi tenaga pendidik dan kependidikan, infrastruktur teknologi dan kapabilitas sistem informasi, (3) Observasi adalah pengamatan langsung terhadap obyek yang diteliti. Dalam hal ini penulis mengadakan pengamatan langsung pada obyek yang akan diteliti yaitu STMIK ProVisi berkaitan dengan tata kelola IT di perguruan tinggi yang diobservasi.

\subsection{Metode Pengembangan Sistem}

Penelitian ini menggunakan metode pengembangan sistem (SDLC) dengan langkahlangkah sebagai berikut:

1. Tahap perencanaan system (system planning)

Kegiatan yang dilakukan pada tahap perencanaan sistem diantaranya : mendefinisikan masalah, menentukan tujuan sistem informasi tata kelola IT berbasis web, mengidentifikasi kendalakendala yang akan dihadapi oleh perguruan tinggi setelah sistem informasi tata kelola IT yang baru diterapkan.

2. Tahap analisis (system analysis)

Kegiatan yang dilakukan pada tahap analisis yaitu mengidentifikasi masalah dan kekurangan pada sistem informasi tata kelola IT berbasis web yang sdah berjalan

3. Tahap perancangan sistem (system design)

Kegiatan yang dilakukan pada tahap perancangan sistem meliputi : Pembuatan permodelan proses, permodelan data dan membuat desain antar muka (interface).

4. Tahap implementasi sistem (system implementation)

Kegiatan yang dilakukan pada tahap implementasi sistem meliputi : menyiapkan hardware dan software, memasang sistem informasi tata kelola IT berbasis web yang baru dan melakukan pengujian sistem yang telah dibuat

5. Tahap Pengujian (Testing)

Sistem informasi tata kelola IT pada perguruan tinggi ini akan diuji pada perguruan tinggi yang diobservasi dimana user yang melakukan pengujian adalah Unit Pusat Komputer (PUSKOM), Ketua Program Studi dan Pembantu Ketua Bidang Akademik pada perguruan tinggi.

\section{Hasil dan Pembahasan}

Penelitian Sistem informasi Tata Kelola IT Berbasis Web, ini dirancang dengan menggunakan Metode Systems Development Life Cycle atau Systems Life Cycle, dalam rekayasa sistem dan rekayasa perangkat lunak, adalah proses pembuatan dan pengubahan sistem serta model dan metodologi yang digunakan untuk mengembangkan sistem-sistem tersebut. SDLC juga merupakan pola yang diambil untuk mengembangkan sistem perangkat lunak, yang terdiri dari tahap-tahap: analisis, desain, implementasi, dan uji coba.

\subsection{Analisis Sistem Lama}

1. Menganalisis Keaandalan

Keandalan menunjukan banyaknya kesalahankesalahan yang dilakukan dalam suatu kegiatan. Semakin andal berarti semakin sedikit kesalahan yang dilakukan. Sistem Tata Kelola IT yang 
masih digunakan di Perguruan Tinggi masih dilakukan secara manual yakni masih dibagikan dan diinputkan excell dan dilakukan perhitungan. Dari segi keamanan, sistem tata kelola IT secara manual masih sangat rawan, sehingga dibutuhkan sistem baru yang dapat bekerja secara optimal untuk meminimalisir kesalahan yang terjadi.

2. Menganalisis Laporan Evaluasi

Laporan Evaluasi dan Monitoring Tata Kelola IT masih dilakukan secara manual dan data yang disajikan masih sering terjadi kesalahan rekap data, sehingga perlu dibuat sistem yang baru untuk mengoptimalkan kinerja

3. Menganalisis Teknologi

Sistem lama di Perguruan Tinggi dalam hal tata kelola IT masih dilakukan secara manual atau tulis tangan sehingga perlu dibuatkan sistem informasi tata kelola IT berbasis web yang didukung dengan kemajuan teknologi saat ini agar perguruan tinggi dapat memperoleh informasi secara tepat dan akurat.

\subsection{Activity Diagram}

Alur Proses Bisnis pada penelitian Sistem Informasi Tata Kelola IT Berbasis Web merupakan pengukuran kinerja dan kegiatan yang telah ditentukan dan akan dimanfaatkan untuk monitoring kinerja dari IT suatu Perguruan Tinggi. Selengkapnya dapat dilihat pada Gambar 2.

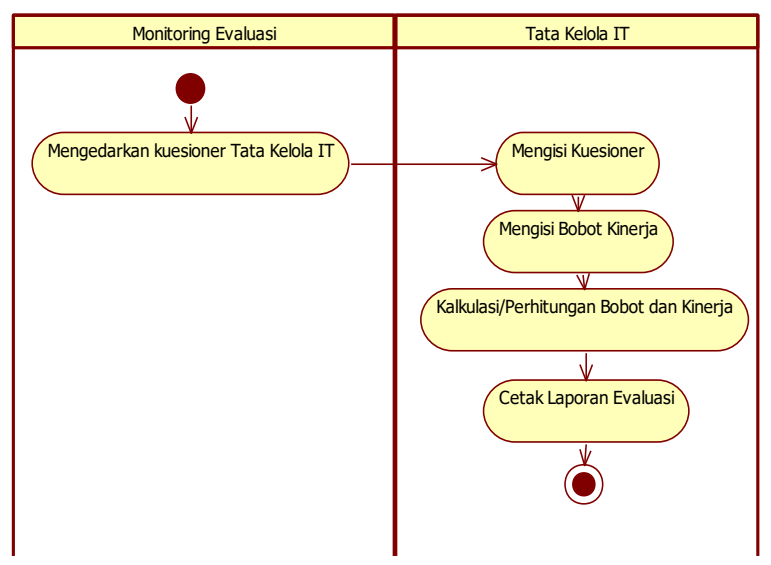

Gambar 2. Activity Diagram
Penjelasan Gambar 2 adalah sebagai berikut:

1. Bagian monitoring akan memberikan kuesioner untuk diisikan sesuai dengan dimensi Balanced Scorecard yang terdiri dari 4 dimensi.

2. Dalam kuesioner yang diberikan, bagian tata kelola IT mengisikan kuesioner yang wajib diisi.

3. Bagian Tata Kelola akan melakukan kalkulasi perhitungan bobot kinerja terlebih dahulu berdasarkan kuesioner yang telah dibagikan. Dari perhitungan bobot kinerja akan dilanjutkan dengan perhitungan KPI untuk mendapatkan kesimpulan hasil kinerja KPI.

4. Proses terakhir adalah akan dicetak hasil evaluasi.

\subsection{Perancangan Sistem}

Perancangan prosedur yang diusulkan akan berorientasi objek dengan menggunakan notasi UML yang berfungsi sebagai alat dokumentasi dan visualisasi. Perancangan sistem yang akan diaplikasikan ini bertujuan untuk menggambarkan secara umum kepada pengguna tentang sistem yang akan dibangun dan mengidentifikasi komponenkomponen sistem informasi yang akan didesain secara rinci.

1. Use Case Diagram

Penelitian ini terdiri dari 3 pengguna, yakni administrator yang melakukan login sistem administrator terlebih dahulu kemudian dari proses login akan memiliki hubungan (dependency) yakni proses mengelola dimensi, mengelola pengguna, mengelola kuesioner. Dependency diartikan bahwa proses-proses tersebut akan bergantung dari proses sebelumnya yakni proses login (Gambar 3). 


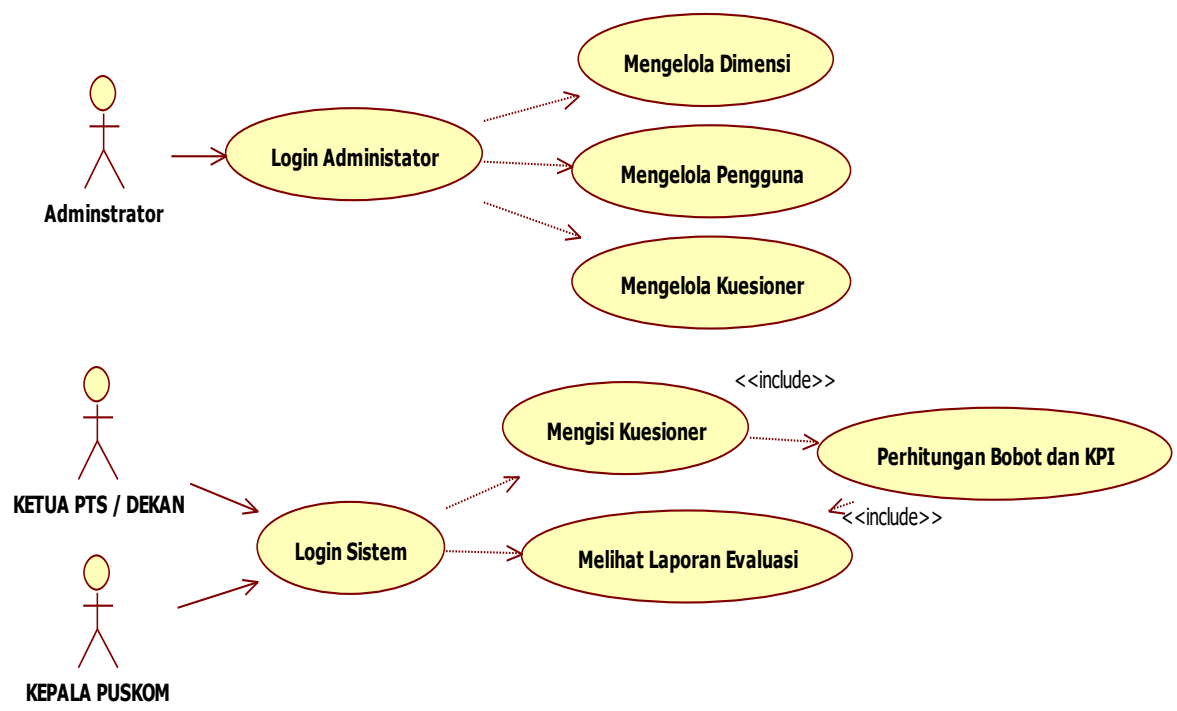

Gambar 3 Use case Sistem Informasi Tata Kelola TI

\section{Class Diagram}

Class Diagram adalah sebuah spesifikasi yang jika di instansiasi akan menghasilkan sebuah objek dan merupakan inti dari pengembangan dan desain berorientasi objek. Class Diagram menggambarkan keadaan (atribut/properti) suatu sistem, sekaligus menawarkan layanan untuk memanipulasi keadaam tersebut (metoda/fungsi). Class Diagram menggambarkan struktur dan deskripsi Class, Package, dan dan Object beserta hubungan satu sama lain seperti containment, pewarisan, asosiasi, dan lainlain.

Berikut adalah Class Diagram yang dibutuhkan dalam perancangan Sistem Informasi Tata Kelola IT Berbasis Web.

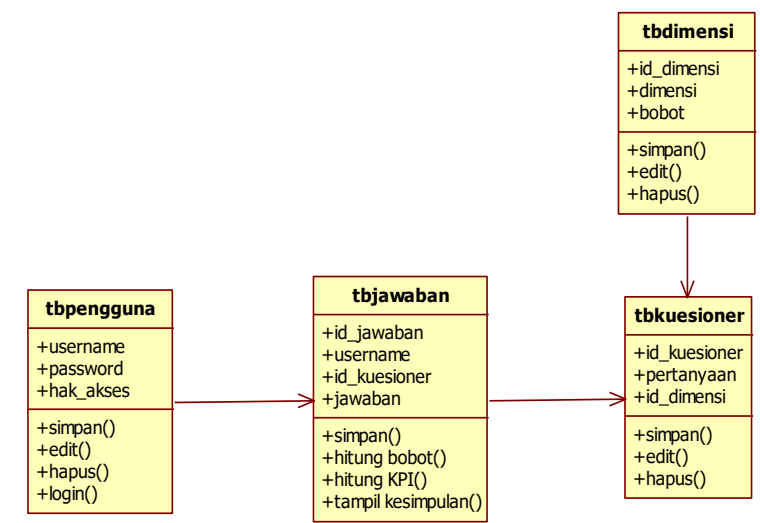

Gambar 4. Class Diagram Sistem Informasi Tata Kelola IT Berbasis Web

\subsection{Implementasi Sistem}

Beberapa menu (user interface) pada tampilan sistem informasi terdiri dari :
1) Login

Pada halaman ini user akan menginput username dan password. Jika username dan password benar makan akan ditampilkan halaman dashboard, jika salah akan muncul pesan password atau username tidak cocok.

2) Dashboard

Halaman dashboard menunjukkan hasil laporan hasil akhir dari pengisian kuesioner. Yaitu laporan corporate contribution, stakeholder orientation, operational excellent, dan future orientation. Dibawahnya ditunjukkan hasil apakah sudah sesuai dengan yang diharpakan atau tidak.

3) Dimensi

Pada halaman dimensi terdapat menu lihat data dan tambah data. Lihat data untuk menunjukkan dimensi data apa saja yang dihitung dan ditampilkan di dashboard. Pada tiap dimensi terdapat menu update, edit dan delete. Update berarti memperbarui dimensi, edit berarti mengedit nama dimensi serta delete untuk menghapus dimensi tersebut. Tambah data nantinya akan tampil form untuk menambahkan dimensi data yang akan dihitung dan ditampilkan sesuai kebutuhan.

4) Daftar Pertanyaan

Daftar pertanyaan berisi pertanyaan apa saja yang diajukan, variable dan action yan berfungsi sebagai update, edit dan delete.

\subsection{Pembahasan}

Penelitian ini menggunakan perancangan database Mysql tersusun dari tabel dimensi, pengguna, jawaban, dan kuesioner. Untuk membangun web pada penelitian ini terdapat 2 adminstrator yaitu admin dan sistem. Laporan transaksi dapat dilakukan setiap akan melakukan audit tata kelola teknologi informasi. Dari rancang bangun tata kelola kinerja perguruan tinggi menggunakan IT balanced scorecard memberikan 
kemudahan pada pihak manajemen perguruan tinggi dalam pengambilan keputusan berinvestasi bidang IT dan mengetahui posisi strategis sumber daya yang dimiliki perguruan tinggi dengan relatif cepat. Hasil simulasi yang dilakukan di salah satu perguruan tinggi menunjukkan : Nilai kinerja rata-rata pada Perspektif Kontribusi Organisasi (Corporate Contribution) sebesar 2,14 dengan target pencapaian sebesar 4 diperoleh nilai KPI sebesar 53,5\% yang dikategorikan tingkat pencapaian yang cukup; (2) Nilai kinerja ratarata pada Perspektif Orientasi Pengguna (User Orientation)_sebesar 3,59 dengan target pencapaian sebesar 4 diperoleh nilai KPI sebesar 89,75\% yang dikategorikan tingkat pencapaian yang baik; (3) Nilai kinerja rata-rata pada Perspektif Keunggulan Operasional (Operational Excellence) sebesar 2,67 dengan target pencapaian sebesar 4 diperoleh nilai KPI sebesar $66,75 \%$ yang dikategorikan tingkat pencapaian yang cukup; $\quad$ (4) Nilai kinerja rata-rata pada Perspektif Orientasi Masa Mendatang (Future Orientation) sebesar 1,77 dengan target pencapaian sebesar 4 diperoleh nilai KPI sebesar $44,25 \%$ yang dikategorikan tingkat pencapaian yang rendah.

\section{Kesimpulan}

Dengan menggunakan sistem informasi rancang bangun tata kelola kinerja perguruan tinggi menggunakan IT Balance Scorecard, pengolahan data lebih cepat dan efisien sehingga lebih cepat dalam pembuatan laporan evaluasi tata kelola IT. Sistem ini dapat membantu penyajian informasi dan pengurangan kesalahan perhitungan. Pada sistem yang berbasis komputer akan mengurangi biaya untuk pembelian alat tulis, karena penyimpanan datanya telah disimpan ke dalam database server yang ada di komputer. Pada sistem ini data tata kelola IT disimpan ke dalam database, dan dapat di backup sehingga data-data transaksi terjaga utuh keamanannya. Sistem ini dapat menyelesaikan proses pembuatan laporan dengan cepat, kurang lebih sekitar 5 menit saja. Sistem ini dapat mempercepat proses perhitungan bobot kinerja dan KPI serta memberikan informasi kesimpulan yang didapat dari Tata Kelola IT Perguruan Tinggi berdasarkan IT Balanced Scorecard.

\section{Terima Kasih}

Terima kasih atas Kementerian Riset dan Teknologi Pendidikan Tinggi (Ristek Dikti) atas pendanaan hibah dosen pemula dan Ketua STMIK ProVisi atas kerjasamanya dalam pengambilan data riset.

\section{Daftar Pustaka}

Gaspersz, V., 2002. Manajemen Kualitas Dalam Industri Jasa, Gramedia, Jakarta.

Grembergen, W.V. and Saull, R., 2001. Aligning business and information technology through the balanced scorecard at a major canadian financial group: its status measured with an it bsc maturity model. Proceeding of the 34th Hawaii International Conference on System Sciences, 199211.

Harsono, O., 2010. Pengaruh strategi bisnis dan strategi teknologi informasi terhadap kinerja lembaga pendidikan: studi kasus perguruan islam al-izhar pondok labu. Jurnal Telematika, 2(1): 5258.

Jogiyanto dan Wily, A., 2011. Sistem Tatakelola Teknologi Informasi. Penerbit Andi Offset, Yogyakarta.

Norton and Kaplan., 2000. The Strategy Focused Organization, Harvard Business School, Boston.

Alberch, B. and Pirani, J.A., 2004. Using an IT Governance Structure to Archieve Alignment at the University of Cincinnati. ECAR Case Study Fourth, 1-18. 